\title{
Current Research on Preservation of Archival Records on Silver-Gelatin Type Microfilm in Roll Form
}

\author{
C. S. McCamy and C. I. Pope
}

(June 9, 1965)

\begin{abstract}
This is a progress report on a study of aging blemishes on microfilm and measures to prevent their formation. Recommendations, based on current information, include: avoiding excessive densities, avoiding physical damage to the film, the use of potassium iodide in the fixer, thorough washing, uniform drying, storage at low temperature and humidity in sealed containers, avoidance of airborne reactants, increased archival use of positive copies, and periodic inspection.
\end{abstract}

\section{Introduction}

One method of preserving records for archival purposes is to photograph the records, producing images of reduced size made up of silver dispersed in a gelatin film, and to keep the film under conditions suitable for its preservation. This method has been in use on a commercial scale for more than a third of a century. In recent years it has been found that blemishes not previously noted developed on some such microfilms years after the films were processed and placed in storage [1]. ${ }^{1}$ Some of these blemishes were described in detail by Henn and Wiest and others by McCamy $[1,2]$. Reference 2 gave recommended procedures for sampling and inspecting film and reporting blemishes. Large numbers of rolls of microfilm in use in the Government have been inspected, utilizing these techniques, and the results of those inspections are being analyzed. The mechanisms of formation of aging blemishes and methods of preventing their formation are being studied at the National Bureau of Standards and in laboratories of the photographic industry. The mechanisms are being elucidated and promising methods of prevention have been proposed. The purpose of this publication is to provide guidance based on the findings to date.

If a document is intrinsically valuable, an archivist may elect to preserve the original as long as he can. Methods of preserving documents have been developed at this Bureau $[3,4,5]$. By preserving a photograph of the document, in a separate place, the preservation of at least the appearance of the document is further assured.

There are a number of other reasons that photography is employed for the preservation of records. Perhaps one of the most obvious is that a camera can reduce the area occupied by the record. Systems commonly used today produce images having areas $1 / 100$ to $1 / 1000$ of the areas of the originals.

1 Figures in brackets indicate the literature references at the end of this paper.
The high costs of buildings, maintenance, filing equipment, and heating and air conditioning prohibit the retention of many original records, but it is feasible to retain the images on microfilm.

Perhaps one of the less obvious reasons for microfilming is that the microphotograph is quite often more stable than the original document. A high grade of paper is not always used in anticipation of the archival value of the document. In the Federal records there are many letters from private citizens or foreign sources. The Government cannot control the quality of paper and ink used in the correspondence it receives.

The classical Government research pertinent to microfilm stability is the paper on the stability of motion picture films published by Hill and Weber in $1936[6,7]$. Since there were at that time some rather old copies of photographs made on silver and gelatin emulsions and the major difficulties had been with the nitrate base, the primary interest was in the base materials. These workers noted that ordinary oven-aging in dry air had no effect on the gelatin emulsion of acetate films as far as could be observed. They tested the stability of cellulose acetate by a number of laboratory procedures and concluded, "While it is not possible to predict the life of acetate film from these resulis, the data show that the chemical stability of the film, with respect to oven aging, is greater than that of papers of maximum purity for permanent records. On the basis of this comparison, cellulose-acetate motion picture film appears to be very promising for permanent records." NBS Miscellaneous Publication M-158, published the following year by the same authors, gave recommended properties of film for permanent records [8]. By Act of Congress, in 1940, the National Bureau of Standards was assigned the responsibility for the maintenance of standards for the reproduction of permanent Government records by microphotographic processes [9]. Subsequent legislation assigned this responsibility to the National Archives in 1943 and to the Administrator, General Services Administration, in $1949[10,11]$. However, as a service, the actual maintenance of the standards 
was continued from 1940 until 1957 by the Photographic Research Section of the National Bureau of Standards. In 1945, the American Standards Association adopted a standard Specification for Photographic Films for Permanent Records based upon the NBS standard [12]. This standard was revised in 1957 [13]. In that year the NBS standard was rescinded and an interim Federal standard was issued, followed by Federal Standard 125a, which simply referenced the American Standards Association standard [14]. Since that time, our research on the stability of photographs has resulted in papers on the chemical mechanisms of fixing, fading, and sulfiding, and chemical analytical techniques for determining residual thiosulfate $[15,16,17]$.

Large numbers of rolls of microfilm processed and preserved at the National Archives are in good condition after many years and have no aging blemishes. This demonstrates that under the right conditions microfilm can be sufficiently stable. It is important to know what conditions of film processing and storage are necessary and sufficient to achieve this stability consistently. These conditions can be stated with confidence only when the mechanism of formation of aging blemishes is fully understood.

\section{Classification of Aging Blemishes}

To promote consistent reporting, the various kinds of aging blemishes have been classified according to six types, as illustrated in the photomicrographs, figures 1 through 6 , and as described below.

Type 1

Type 1 are circular spots, usually 50 to $150 \mu$ in diameter, with sharp boundaries. Concentric light and dark rings are common. Spots normally occur as reduced density in high-density "background" areas, but may make incursions into low-density lines or characters. They are usually brown, orange, reddish, or yellow in color. It is common to find many spots about the same size on a sample. The spots are often seen centered on scratches in the emulsion, sometimes closely packed, like beads on a string. They sometimes occur in higher concentration at steep density gradients, sometimes giving the appearance of a continuous band. By reflected light, the spots may display a silvery sheen.

Type 2

Type 2 are defects in the light lines forming the characters themselves, rather than in the high-density "background." The lines making up the characters become lighter, yellowish, and broader. The boundaries of the defect are sharp.

Type 3

Type 3 are about 10 to $15 \mu$ across. When they occur, there is usually a large number per unit of area. They usually range from pale yellow to orange in color. Their boundaries are sharp. By reflected light, the spots may display a silvery sheen.

\section{Type 4}

Type 4 are spots of less regular shape than type 1 but a little larger, usually lighter in color, and less sharply bounded. A circular central "nucleus" is common. These spots occur in high-density "background" areas. 'They do not make incursions on low-density characters; on the contrary, their shapes may be very distorted to accommodate to the spaces between characters or parts of characters.

Type 5

Type 5 is a reddening of the dark background in the immediate neighborhood of lighter characters. The boundaries of the discoloration are very diffuse. The shape is not regular, being determined by the shape of the characters or line of characters with which the discoloration is associated.

Type 6

Type 6 is a reddish, orange, or yellow spot of reduced density, lightest at the center and gradually blending into the surrounding background. An irregular opaque or crystalline particle is commonly observed on the surface of the film at the center of the spot. The sizes of the spots may vary considerably, even within a small region.

\section{Film Inspections}

Large numbers of rolls of Federal record film were inspected, but it would have been impossible for us to inspect a sizable fraction of federally held microfilm in a reasonable time. Therefore, in cooperation with the National Archives, about 100 employees of other Government agencies were trained to inspect films and report their findings. The procedures followed were those given in reference 2 . To date over 7,000 rolls of film, representing a sampling of about 10 million rolls, have been inspected and reported. The information is being encoded for a detailed statistical study by means of a digital computer. This study will quantitatively evaluate the interrelationship of all variables considered to be of importance at the time the inspection program was begun. Though this analysis may reveal trends not now known, the reports have shown no obvious indications of conditions greatly different from those encountered in the initial NBS inspections, upon which the following observations are based.

Aging blemishes were observed on microfilm in roll form but not on other films, with the following exceptions. Two instances involved film on nitrate base, a type of base which has not been in use in this country for many years. One was 9-in. aerial film about 25 years old, the other was $35 \mathrm{~mm}$ motion picture film about 50 years old. The spots on the aerial film looked like Type 1 blemishes but the others resembled general fading more than aging blemishes. A collection of $2 \frac{1}{2}$-in. square (No. 120) pictorial negatives on a fine-grain roll-film manufactured, exposed, processed, and stored in Europe was very badly affected. No blemishes have been reported on such pictorial negatives in this country. Blemishes have been reported on some microfilm 


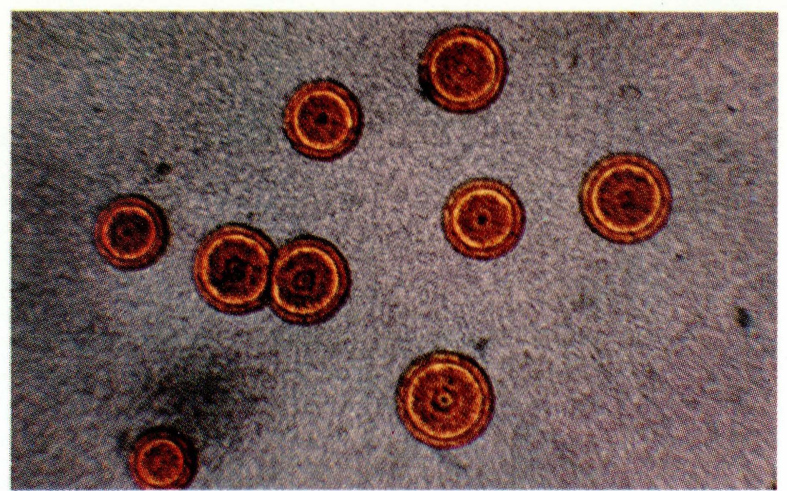

1

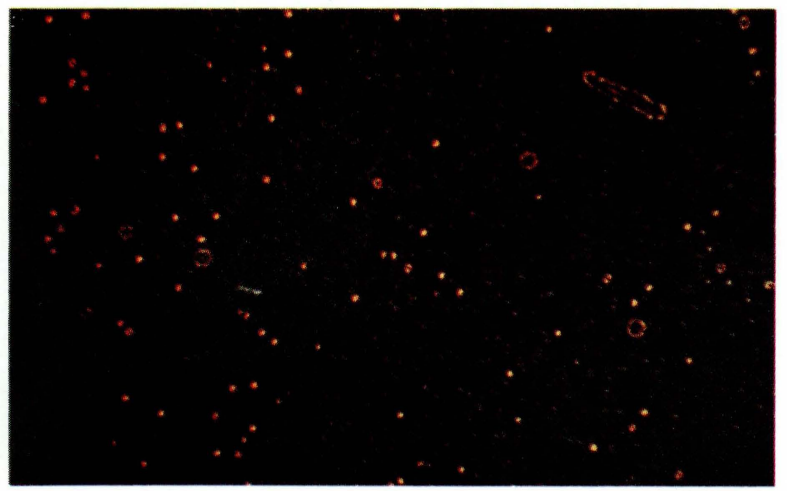

3

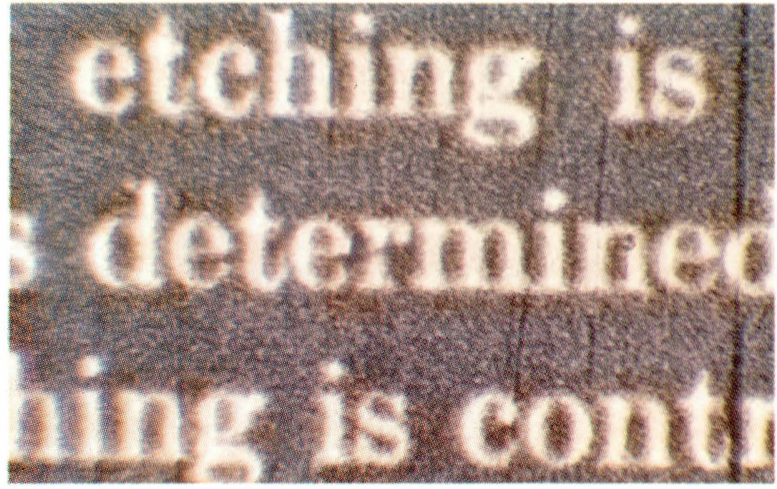

5

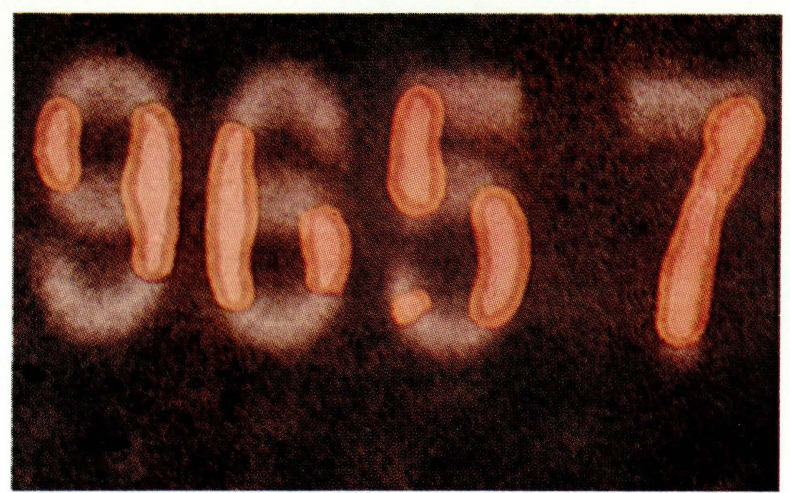

2

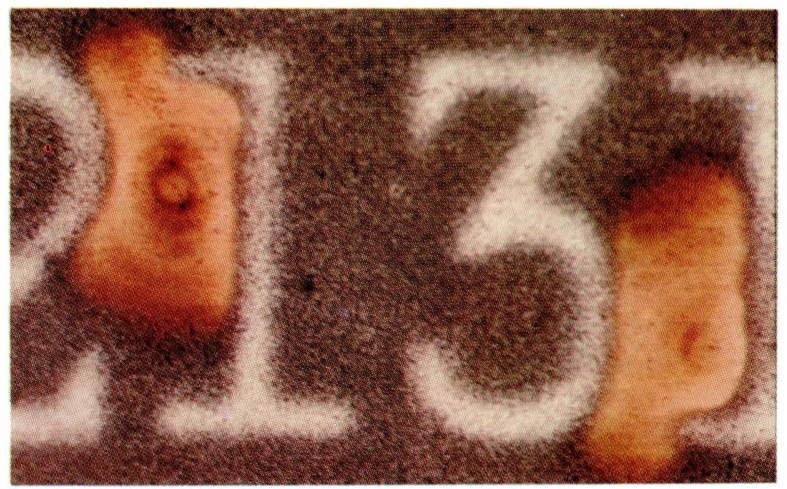

4

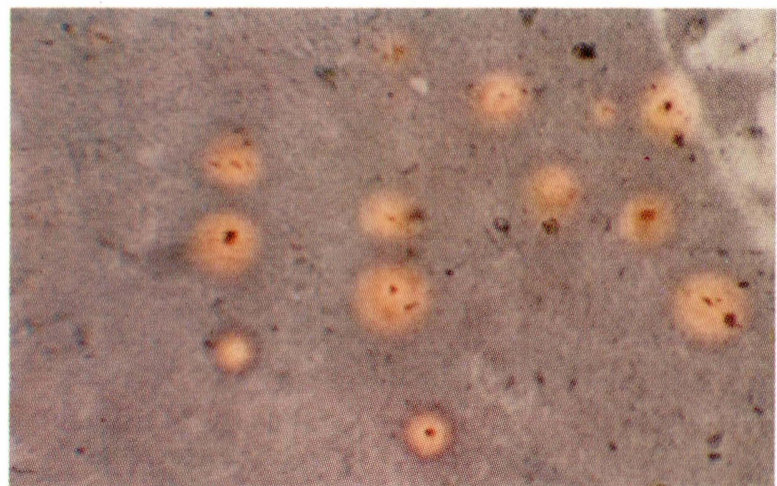

6

Figure 1. Type 1. On the record film, the spots shown range from 120 to 170 microns in diameter.

Figure 2. Type 2. On the record film, the height of the numbers is 180 microns.

Figure 3. Type 3. On the record film, the spots are about 15 microns across.

Figure 4. Type 4. On the record film, the height of the numbers is 240 microns.

Figure 5. Type 5. On the record film, the height of the lower case letters is 120 microns.

Figure 6. Type 6. On the record film, these spots range from 30 to 110 microns in diameter. 
chips mounted on aperture cards. About 35,000 positive microfilm chips mounted on aperture cards were accumulated in our office between 1953 and 1957. This collection has been exposed to ordinary office conditions, with air conditioning during the summer months. The collection was recently inspected and no aging blemishes were found. Further studies of films on aperture cards have been initiated.

Aging blemishes were not observed on the information areas of positive copies having dark characters on a light background, although aging blemishes have been observed on the high-density borders of such films.

Microfilm was found stored on reels made of plastic, painted steel, anodized aluminum, and fiberboard. Some was stored on cores, without flanges, made of plastic or wood.

The film was stored in cardboard boxes, one reel to a box. Most boxes were those generally supplied commercially, but some agencies, such as the National Archives, had boxes specially made for their use. The boxes of film were usually stored in shallow drawers in painted steel cabinets, or on painted steel shelves.

With a few exceptions, blemishes were not observed on the outer convolution of film. The pattern of blemishes began, often abruptly, at the beginning. of the second convolution. The most frequent exception was the observation of a pattern of blemishes beneath a rubber band, string, or adhesive tape, used to bind the roll.

On a given small area on a film, the spots of Types 1 and 3 very often displayed a remarkable uniformity of size. The general features of the outer rings of ringed spots also tended to display similarity over a small spatial range.

Given the conditions for blemish formation, blemishes appeared to form more readily at higher densities. Several instances were found in which a number of frames in a row had numerous blemishes, while a frame in their midst having a lower density was free of blemishes. Conversely, a denser frame with blemishes has been observed among lower density frames without blemishes. A series of consecutive frames had blemishes concentrated within a rough arc centered at one side of the frame (not a side at the edge of the film). Apparently the illuminance had been higher on one side of the original documents, because there was a consistent pattern of higher density within a rough are on that side. When the leaders were fogged they were the densest parts of the films and typically had many more blemishes than other areas on the film.

Even the types of aging blemishes not regarded as character associated, such as Type 1, were often concentrated at places corresponding to high gradients of density. The straight boundary between the dense backoround of a filmed document and the clear space between frames was sometimes marked by a nearly solid line of blemishes.

Type 1 and Type 3 blemishes were often observed in a nearly continuous string along scratches in the emulsion.

In a series of frames of copies of reports or other documents on identical forms, Type 2 blemishes were observed on the corresponding characters of as many as 25 consecutive frames.

In one file of film about 30 years old, of which there was no processing or early storage history, there was a consistent high incidence of Type 1 blemishes, except on a few rolls that had no blemishes. The only known storage difference between the unblemished films and the others was that each reel of unblemished film was surrounded by a strawboard band, dark grayish yellow in color. A typical band measured $1.25 \mathrm{~mm}$ thick, $303 \mathrm{~mm}$ long, and $22.6 \mathrm{~mm}$ wide - too wide to fit between the flanges of the $16 \mathrm{~mm}$ reel. The band was wrapped around the outer edge of the reel. Such bands have not been observed elsewhere. The strawboard was quite alkaline, having a $p \mathrm{H}$ of about 9 , whereas the cardboard in the storage boxes tested was acid, having a $p \mathrm{H}$ of 4 to 6 . The strawboard had a lower concentration of rosin than any of the box stock tested. The strawboard was so brittle that it broke when bent $45 \mathrm{deg}$ over a support with a $4-\mathrm{mm}$ radius of curvature.

In the course of inspections, it was discovered that in a number of instances on one roll, blemishes were arrayed in closed or nearly closed rings. Such formations were called "atolls." On the same roll, barely perceptible water spots were observed. The faint water spots on the back of the film were coincident with atolls of the same size and shape on the emulsion side of the next convolution. An example of this phenomenon was sent to John Calhoun at Eastman Kodak Company, who had an analysis made of the residue at the edge of the water spot. The analysis revealed nothing more than a minute residue of the minerals commonly found in water and a trace of sulfate ion.

One of the most significant findings was a collection of about 37,500 rolls of $35 \mathrm{~mm}$ microfilm without blemishes. This film was exposed, processed, and stored at the National Archives. It was manufactured by two different American manufacturers since 1940 .

Two aspects of the processing at the National Archives are considered notable: the presence of an exceptional amount of iodide ion in the fixing bath and an exceptionally high rate of wash water consumption per unit of film area. The iodide in the fixing bath presumably resulted from the processing of considerable amounts of positive film along with negative film.

The blemishes had a lower visual optical density than the normal background, and a spectral transmittance higher at long wavelengths than at short wavelengths in the visible spectrum. Because of this spectral transmittance and the ultraviolet and blue sensitivity of photographic copying materials, the printing density was much higher than the visual density. As a consequence, the blernishes were often not noticed on photographic prints of films having 
blemishes and the legibility of the prints appeared better than that of the blemished film. This effect can be observed directly by placing a deep blue filter, such as Wratten No. 47, over the light souce and examining the film with a microscope. The legibility of films badly damaged by Type 2 blemishes has been greatly improved by this technique.

A certain roll of negative film was manufactured In 1936 and processed in 1936 or 1937. A copy of the film was made between 1936 and 1944, one in 1958, and another in 1963. Albert H. Leisinger, Jr., of the National Archives obtained the original and the copies and photographed corresponding frames of each, with a magnification of about 20 . The pre-1944 copy showed no noticeable blemishes. The 1958 copy revealed about 300 Type 1 blemishes on the negative. The 1963 copy exhibited no increase in the number of spots but some growth in the diameter of spots. The ratio of diameters ranged from 1.5 to 2 .

One of the objectives of the initial film inspections was to find the extent to which Government films were affected by blemishes and to ascertain whether or not any information had been lost. Of the total number of collections of microfilms, a large fraction had some blemishes. In those collections having blemishes, a fraction of the rolls were involved. On a roll, blemishes sometimes were and sometimes were not on the information frames. When blemishes occurred on information frames, only a fraction of the frames were affected. On a blemished frame, only a fraction of the blemishes were on or around characters. Of the six types, only the infrequently occurring Type 2 formed in the characters, although Type 1 sometimes crossed over parts of characters. Other types showed a natural aversion to attacking characters. As a result of the redundancy of the records, the statistical distribution of blemishes, and the characteristics of the mode of formation of blemishes in the vicinity of characters, the amount of loss of information in Federal records appeared to be extremely small. Nonetheless, one agency reported some such loss in the only existing copies of certain reports having tabulated numerical data. The only observed cases of actual loss of information resulted from Type 2 blemishes.

P. R. Achenbach and C. W. Phillips (of the Building Research Division), who are experienced in heating and air conditioning engineering, examined a few Government microfilm storage facilities. They found that the buildings were not always well designed for the purpose, air conditioning was not always adequate, and the practice of monitoring temperature and humidity at a central location in a room did not always assure proper control of these variables at the perimeter of the room where some of the films were stored. There were indications in some cases that moisture had condensed on the inner surfaces of outside walls where storage cabinets had been placed against the walls, preventing free circulation of air. The humidity obviously becomes too high for good microfilm storage at the back of a cabinet under such conditions.
In every major respect, the reports of inspections described by Henn and Wiest [1] were verified. Their inspections included privately held microfilms while ours were limited to Government records. There was some duplication of the collections inspected but the inspections were entirely independent. The Eastman Kodak Company called the discovery of blemishes to our attention and we adopted classification terminology consistent with theirs, extending it somewhat, so that our reports could be readily compared.

\section{Experimental Research}

\subsection{Structure of Blemishes}

The structure and chemical nature of typical blemishes have been described by Henn and Wiest [1]. The irregular granular pattern characteristic of normal photographic image silver is absent in the light colored areas of the blemishes. The whole thickness of the image layer is generally involved.

Samples of microfilm having Type 1 blemishes $20 \mu$ to $50 \mu$ in diameter were redeveloped in a metolhydroquinone developer and washed. The color of the spots changed from light yellow to a deeper yellow, orange, or reddish orange. A still deeper color was obtained when the samples were treated in a 0.1 percent solution of either potassium bromide or potassium iodide. These results suggest that silver ions, silver gelatinate, or both are present in the spots and that they may be reduced to silver.

When samples of blemishes were fixed in sodium thiosulfate, they became lighter in color but the grainy dark rings remained. This result indicates that some ionic silver may be removed from the colored areas but that much of the color is attributable to colloidal silver.

When a normal microfilm image is bleached to a yellow color by gaseous hydrogen peroxide, the yellow color cannot be entirely removed by bathing in sodium thiosulfate. This implies that much of the color is attributable to colloidal silver, since silver ions would presumably be removed.

Film samples with Type 1 blemishes were treated in a solution of 2.5 percent mercuric chloride and 2.5 percent potassium bromide, washed in a very dilute hydrochloric acid solution, and then developed. The dark concentric rings and dark rims of the spots were greatly intensified, indicating that these rings are largely made up of silver grains.

Samples were bleached in a solution of $5 \mathrm{~g}$ of potassium dichromate and $5 \mathrm{ml}$ of concentrated sulfuric acid per liter, cleared in a solution of $50 \mathrm{~g}$ of sodium sulfite and $1.0 \mathrm{~g}$ of sodium hydroxide per liter, fixed in a solution of $240 \mathrm{~g}$ of sodium thiosulfate per liter, and washed. The light brownish silver sulfide image normally remaining after a dichromate bleach was observed in the normal image areas. The spots were a darker brown in the center, in the dark concentric rings, and in the dark outer rims, indicating. concentrations of silver sulfide in these areas. A permanganate bleach made the spots colorless and 
difficult to observe in the gelatin, removing all granular silver, colloidal silver, and silver sulfide.

Type 1 blemishes were scanned with an electron probe and the characteristic $\mathrm{x}$-radiation of silver was monitored. The scans revealed silver in the light areas but much more in the dark concentric rings and dark rims of spots.

\subsection{General Mechanism}

The currently favored hypothesis is that blemish formation is a chemical reaction in which the normal silver grains are corroded away, the silver ions migrate, and are in large part redeposited as colloidal silver or as mirrorlike deposits of silver and silver sulfide at the upper or lower surface of the gelatin layer. Considerable evidence obtained here and elsewhere supports this hypothesis [1]. An oxidation reaction of some kind is required to ionize the metallic silver and a reduction reaction is required to redeposit the silver. Peroxides can bring about oxidation-reduction reactions with silver so it is natural to suspect that blemishes are formed by peroxides attacking the image silver [1]. Why the attack should be localized and why the blemishes should assume their typical forms are not entirely clear. The heavy concentration of blemishes along scratches in the gelatin may be attributed to the removal of the protective gelatin layer. Any weakness in the gelatin layer, in the sense of permeability to chemicals or concentration of reactive or catalytic species could determine the site of attack. In the normal image, the nature of the gelatin depends on the local density of image silver. The local concentrations of various chemicals, such as thiosulfates, retained in the image also depend on the local image density. For these reasons, the strong influence of the image upon the location and form of blemishes is consistent with the working hypothesis.

\subsection{Liesegang Ring Phenomenon}

The very concentric ring patterns in the Type 1 blemishes and less regular concentric ring patterns in Type 4 blemishes are strongly reminiscent of the phenomenon first described by R. E. Liesegang [18, 19] and known as Liesegang ring formation. K. H. Stern, of NBS who has had wide experience with this type of reaction, [20] considered the Type 1 blemish to have typical Liesegang ring structure, although Liesegang rings are generally produced on a larger scale.

The classic experiment of Liesegang was repeated using a microscopic droplet of silver nitrate solution on a gel layer containing potassium dichromate. The reaction proceeded as Liesegang reported, but in this case formed a concentric ring pattern in the size range of 'Type 1 aging blemishes, proving that the phenomenon is demonstrable on this scale. A gel layer containing silver sulfide formed 8 concentric rings in 30 days under the action of a single minute droplet of a metol-hydroquinone developer solution. The literature of Liesegang phenomena abounds in references to rings formed in reactions with silver salts in gelatin. Thus, the ring structure in aging blemishes is not fully explained but neither is it unprecedented in silver-gelatin systems. It is likely that the mechanism is the same as that producing Liesegang rings in general.

\subsection{Experimental Control of Temperature and Humidity}

To obtain various conditions of temperature and humidity for experimental purposes, various saturated salt solutions were placed in closed containers which were placed in ovens thermostatically controlled at various temperatures [21, 22, 23]. Because of the large numbers of containers involved in the current survey of a wide variety of effects, the usual technique of stirring the atmosphere in the containers was dispensed with. Inaccuracy in humidity determination is known to result from failure to stir the solution and from contamination of the solution, but for the purpose of the present study the relative humidities produced by various saturated salt solutions were taken to be those given in table 1 and, accordingly, the relative humidities given elsewhere in this report must be considered approximate. Temperatures above room temperature were controlled within a range of $2{ }^{\circ} \mathrm{C}$.

TABLE 1. Percent relative humidity over saturated salt solutions, for various temperatures

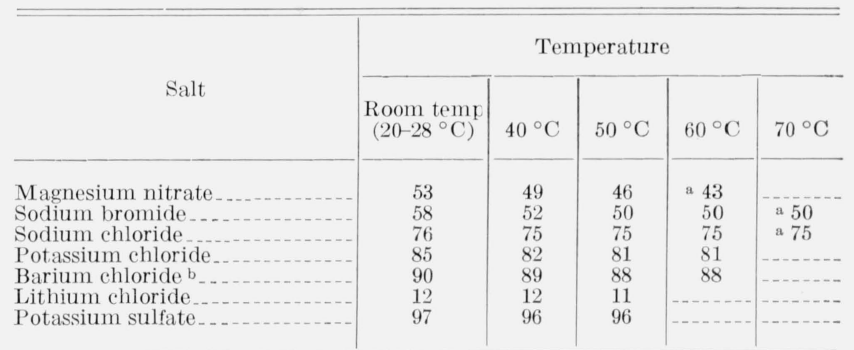

a By extrapolation

b Humidities calculated from vapor pressure data for barium chloride solutions in International Critical Tables, Vol. III, (1928), p. 368.

\subsection{Effect of Imbibed Chemicals on Film Exposed to Hydrogen Peroxide}

Processed and dried microfilm samples were treated $3 \mathrm{~min}$ in 0.1 percent solutions of various compounds, some of which might be found in processing solutions or wash water. It is estimated that the concentration of the compounds was about $8 \mu \mathrm{g} / \mathrm{cm}^{2}$ on the films. The excess solution was shaken from the samples, which were then placed in a 16-oz jar and stored at $60{ }^{\circ} \mathrm{C}$ and a relative humidity of 43 percent over a solution of $40 \mathrm{~g}$ of magnesium nitrate $\left(\mathrm{Mg}\left(\mathrm{NO}_{3}\right)_{2} \cdot 6 \mathrm{H}_{2} \mathrm{O}\right)$ and $5 \mathrm{ml}$ of 30 percent hydrogen peroxide in $10 \mathrm{ml}$ of water. Spots ranging from pinholes to the size of natural aging blemishes formed. The results are given in table 2 . Corresponding control samples without this treatment formed no blemishes under the same storage conditions.

\subsection{Experiments With Dry Chemical Contaminants}

Various dry salts were ground to a powder and the emulsion sides of dry microfilm samples were pressed against the powder and tapped gently to 
remove loose powder. The films were stored in $16-\mathrm{oz}$ jars at $60^{\circ} \mathrm{C}$ and 43 percent rh. Irregular but generally round spots formed. The results are given in table 3. Corresponding control samples without this treatment formed no blemishes under the same conditions of temperature and humidity.

TABLE 2. Effect of various imbibed chemicals on microfilm stored in the presence of hydrogen peroxide

\begin{tabular}{|c|c|c|}
\hline Compound & Time & Effect \\
\hline $\begin{array}{l}\text { Aluminum potassium sulfate } \\
\text { Boric acid } \\
\text { Calcium carbonate. } \\
\text { Cupric acetate } \\
\text { Cupric carbonate } \\
\text { Magnesium sulfate } \\
\text { Mono-methyl-para-aminophenol sulfate. } \\
\text { Potassium bromide } \\
\text { Sodium chloride. } \\
\text { Sodium nitrate } \\
\text { Sodium silicate } \\
\text { Sodium sulfite }\end{array}$ & $\begin{array}{l}h r \\
17 \\
18 \\
72 \\
17 \\
72 \\
17 \\
18 \\
72 \\
18 \\
17 \\
72 \\
17\end{array}$ & $\begin{array}{l}\text { Light yellow spots. } \\
\text { Light yellow spots. } \\
\text { Yellow spots. } \\
\text { Image bleached. } \\
\text { Image nearly bleached. } \\
\text { Light yellow spots. } \\
\text { Yellow spots. } \\
\text { Yellow spots. } \\
\text { Yellow spots. } \\
\text { Light yellow spots. } \\
\text { White and yellow spots. } \\
\text { Light yellow spots. }\end{array}$ \\
\hline
\end{tabular}

TABLE 3. Effect of various powdered chemicals on microfilm

\begin{tabular}{|c|c|c|c|c|}
\hline Chemical & Temp. & $\begin{array}{l}\text { Relative } \\
\text { humidity }\end{array}$ & Time & Effect \\
\hline $\begin{array}{l}\text { Ferric sulfate } \\
\text { Potassium bromide } \\
\text { Potassium iodide..- } \\
\text { Sodium chloride } \\
\text { Sodium thiosulfate } \\
\text { Sulfur... }\end{array}$ & $\begin{array}{l}{ }^{\circ} C \\
60 \\
60 \\
60 \\
60 \\
60 \\
50\end{array}$ & $\begin{array}{l}\% \\
88 \\
88 \\
88 \\
88 \\
43 \\
88\end{array}$ & $\begin{array}{c}\text { Days } \\
11 \\
4 \\
4 \\
4 \\
6 \\
4\end{array}$ & $\begin{array}{l}\text { Yellow spots. } \\
\text { None. } \\
\text { Gray spots. } \\
\text { None. } \\
\text { Yellow spots. } \\
\text { Yellow spots with dif- } \\
\text { fuse edges. }\end{array}$ \\
\hline
\end{tabular}

\subsection{Biological Studies}

Several samples of various kinds of blemishes were studied by E. H. Zeitler at the Armed Forces Institute of Pathology. Employing a variety of staining techniques and methods of microscopic examination, he found no remains of microorganisms or evidence of attack by microorganisms. Henn and Wiest reported that no bacteria or fungi were present in their samples [1].

In our laboratories, dried spores were obtained from cultures of fungi grown in a gelatin solution.

Samples of microinlm were contaminated by brushing dry spores onto the surface and by bathing them in water containing spores. They were stored at 46 percent and 75 percent rh at room temperature and at $50{ }^{\circ} \mathrm{C}$, in desiccator jars. Some fungal growth was observed at 75 percent rh at room temperature but no blemishes appeared during a storage period of 9 months.

Contaminated film was treated with the fungicide, sodium pentachlorophenol $(2 \%)$, and stored at 46 percent $\mathrm{rh}$ and $50{ }^{\circ} \mathrm{C}$. A few spots formed on the control sample after 29 days exposed to peroxide.

Contaminated films stored at 90 percent rh and 97 percent rh and room temperature were so badly attacked by fungal growth that the gelatin was consumed, but at no time did spots form.

In no case were spots formed by the spores. Although spore incubation might weaken the gelatin and invite attack, this effect has not been observed.
Bacterial action by a few organisms on the gelatin surface, perhaps during drying, seemed a possible precursor of attack. Evidence of such activity has not been observed, though it should be detectable if present.

\subsection{Experiments With Peroxides}

During the biological experiments, one control sample unexpectedly developed spots. 'The desiccator jars stored at $50{ }^{\circ} \mathrm{C}$ had a small amount of a stop-cock grease on the rim to secure a vaportight seal, while those stored at room temperature had petrolatum on the rims. It soon became apparent that spots formed in the presence of the stopcock grease. A few spots had developed in 79 days on the control sample stored at 46 percent rh and $50{ }^{\circ} \mathrm{C}$. With more grease around the top of the jar in other experiments, spots developed in 2 to 4 weeks at 46 percent $\mathrm{rh}$ and $50{ }^{\circ} \mathrm{C}$.

This grease had a very faint odor of rancid vegetable oil. The mass spectrograph detected nothing more than water in the vapor. Infrared spectra of the grease itself and the iodine number were used to identify it as castor oil hydrogenated about 30 percent. The double bond compounds of the kinds found in castor oil form peroxides with the oxygen in the air and polymerization bonding of a molecule with another double bond molecule releases hydrogen peroxide which may react with the image silver.

The interior of some desiccator jars was coated about $1 / 8$ in. thick with this grease, from the top to the porcelain plate near the bottom. Microilm samples were stored at various temperatures and humidities. The results are given in table 4 . In all of these tests, it was noted that the areas of the samples closest to the grease surface were affected first. The spots formed in the presence of this grease were visually indistinguishable from naturally occurring spots.

TABLE 4. Effect of fumes of hydrogenated castor oil on microfilm

\begin{tabular}{c|c|c|l}
\hline \hline Temp. & $\begin{array}{c}\text { Relative } \\
\text { humidity }\end{array}$ & Time & \\
\cline { 1 - 1 } & & & \\
\cline { 1 - 2 }$C$ & $\%$ & Days & \\
25 & 58 & 60 & Many spots. \\
25 & 76 & 60 & No spots. \\
40 & 52 & 21 & Many spots. \\
40 & 75 & 29 & Many spots. \\
50 & 11 & 90 & No spots but appreciable general bleaching. \\
50 & 50 & $10-15$ & Many spots, general bleaching. \\
50 & 75 & $15-20$ & Many spots, general bleaching. \\
60 & 50 & $7-10$ & Many spots. \\
60 & 75 & $7-10$ & Many spots. \\
60 & 88 & $7-10$ & Many spots. \\
& & & \\
\hline
\end{tabular}

The unsaturated compounds in linseed oil and castor oil and oleic and linoleic acids were tested for their ability to form spots on film. Linseed oil and linoleic acid caused numerous spots in 25 days at 50 percent $\mathrm{rh}$ and $50{ }^{\circ} \mathrm{C}$ on samples close to the oils. These experiments were done in $16 \mathrm{oz}$ jars having small openings to permit the influx of air. In large unvented desiccator jars the reaction was less severe. The results are given in table 5 . 
TABLE 5. Effect of fumes of several oils and acids on microfilm in closed desiccator jars

\begin{tabular}{|c|c|c|c|c|}
\hline Test substance & Temp. & $\begin{array}{l}\text { Relative } \\
\text { humid- } \\
\text { ity }\end{array}$ & Time & Effect \\
\hline $\begin{array}{l}\text { Linseed oil ......... } \\
\text { Linoleic acid } \\
\text { Castor oil } \\
\text { Oleic acid }\end{array}$ & $\begin{array}{l}{ }^{\circ} \mathrm{C} \\
50 \\
50 \\
60 \\
50 \\
60 \\
50\end{array}$ & $\begin{array}{l}\% \\
50 \\
50 \\
75 \\
50 \\
50 \\
50\end{array}$ & $\begin{array}{l}\text { Days } \\
24 \\
70 \\
28 \\
63 \\
55 \\
63\end{array}$ & $\begin{array}{l}\text { Few spots. } \\
\text { Slightly more spots. } \\
\text { No spots. } \\
\text { No spots, slight yellowing } \\
\text { A few spots. } \\
\text { Very few spots. }\end{array}$ \\
\hline
\end{tabular}

Corresponding control samples formed no blemishes under the same storage conditions.

Films were exposed to turpentine in large vented desiccator jars at room temperature with the following results: 58 percent rh, general bleaching in 35 days; 76 percent rh, general bleaching and spots in 9 days; 90 percent rh, heavy yellow and red coloration, general bleaching, and yellow spot formation in 4 to 5 days; 97 percent rh, considerable general image bleaching but no spot formation in 4 days.

The effects of dipentene, pinene, and turpentine were compared in separate closed desiccator jars at room temperature and 90 percent rh. At 9 days the attack was about the same, with turpentine showing slightly stronger attack.

Varsol, acetaldehyde, gasoline, and formaldehyde caused no spots in 28 days at 90 percent rh and room temperature. Benzaldehyde produced a slight yellowing of the image in 9 days at 85 percent $\mathrm{rh}$ and room temperature.

Films were exposed to powdered rosin placed in culture dishes in closed desiccator jars. At 85 percent rh and room temperature, heavy image bleaching and a few spots were observed at 6 days and an increase in bleaching and formation of reddish spots at 15 days. At 58 percent $r h$ and room temperature, weak general bleaching was found at 2 days and considerable yellowing and many spots, including Type 3 , at 5 days. A sample given the gold treatment of Henn and Wiest [1] showed slight yellowing at 5 days. Abietic acid, the chief constituent of rosin, is known to form peroxide under certain conditions of temperature and humidity.

Similar tests with cinnamaldehyde at room temperature and 85 percent rh caused almost complete general bleaching of the image and formation of an orange color in 7 days (in a $16 \mathrm{oz}$ jar) and at 58 percent rh heavy bleaching and the formation of large bright yellow spots after 13 days (in a large desiccator jar).

A solution of titanium sulfate turns yellow in the presence of a very small concentration of hydrogen peroxide in the atmosphere. A $10-\mathrm{ml}$ beaker of this test solution was placed in a desiccator jar coated with the stop-cock grease and stored at 58 percent $\mathrm{rh}$ and room temperature. The yellow color was appreciable after $24 \mathrm{hr}$. Turpentine, pinene, and dipentene triturated with water gave a strong indication of peroxide after 30 to $60 \mathrm{~min}$. Powdered rosin from one of the aging tests was dissolved in a sodium hydroxide solution and acidified with acetic acid. The solution contained peroxide according to the iodide-starch test. (The solution of rosin is too yellow to permit use of the titanium method.) Tests with known concentrations of hydrogen peroxide showed that the titanium method detected about $15 \mu \mathrm{g}$ of hydrogen peroxide in $25 \mathrm{ml}$ of water and the iodide-starch test detected about $20 \mu \mathrm{g}$ per $25 \mathrm{ml}$ of water. Nitrites and compounds of chlorine may also give a positive indication with the iodidestarch test.

\subsection{Experiments With Cardboard}

Rosin is widely used in paper making although the concentration may be only a few percent. Cardboard may contain natural resins. Alum is often added to papers, creating an acid condition favoring peroxide formation. Furthermore, Marraccini and Kleinert report that measurable amounts of peroxide form in the natural aging of commercial paper pulps and that the peroxide formation rate is related to fiber length [25]. They have described a method of measuring the minute amounts of peroxide [24] and have found peroxide formation to increase with humidity and the total amount of peroxide to increase linearly with time of aging [25]. Peroxide formation follows one mechanism in the presence of air and various others in the absence of air [26]. All of these facts strongly suggest that minute amounts of peroxides generated in the aging degradation of the boxes in which the film is stored can cause aging blemishes under some conditions.

To obtain further evidence on this point, microfilm was aged in contact with cardboard from microfilm storage cartons. Cartons marketed by five major American suppliers and one foreign supplier were used. Both old and new cartons were used. Some films were clamped between two pieces of cardboard. Others were stapled to the carton to hold the emulsion against the cardboard. Some were stored in the presence of acetic acid vapor; others were stored without acid.

Films were clamped between pieces of cardboard and stored under various conditions. The results are given in table 6 . Corresponding control samples formed no blemishes under the same storage conditions. In the test at 50 percent $\mathrm{rh}$ and $70{ }^{\circ} \mathrm{C}$, one spot was evident at 28 days; when the humidity was changed to 75 percent, many spots, some quite large, formed in 6 days.

TAвLE 6. Effect of cardboard strips on microfilm

\begin{tabular}{|c|c|c|c|}
\hline Temp. & $\begin{array}{l}\text { Relative } \\
\text { humidity }\end{array}$ & Time & Effect \\
\hline $\begin{array}{l}{ }^{\circ} \mathrm{C} \\
50 \\
50 \\
50 \\
50 \\
70\end{array}$ & $\begin{array}{c}\% \\
75 \\
81 \\
81 \\
96 \\
50 \text { then } 75\end{array}$ & $\begin{array}{c}\text { Days } \\
28 \\
14 \\
28 \\
28 \\
28 \text { then } 6\end{array}$ & $\begin{array}{l}\text { Few faint spots. } \\
\text { Very few yellow spots. } \\
\text { Few yellow spots. } \\
\text { No spots. } \\
\text { One spot; then many spots. }\end{array}$ \\
\hline
\end{tabular}


Films were clamped between pieces of cardboard from film storage boxes, and were placed in desiccator jars with acetic acid in the humidistat solution. The results are given in table 7 . Corresponding control samples formed no blemishes under the same storage conditions.

TABLE 7. The effect of cardboard on microfilm in the presence of acetic acid vapor

\begin{tabular}{|c|c|c|c|c|}
\hline $\begin{array}{l}\text { Acetic } \\
\text { acid }\end{array}$ & Temp. & $\begin{array}{c}\text { Relative } \\
\text { humidity }\end{array}$ & Time & Effect \\
\hline $\begin{array}{r}\% \\
3 \\
3 \\
2 \\
2 \\
2 \\
2 \\
2 \\
2 \\
2\end{array}$ & $\begin{array}{l}{ }^{\circ} C \\
50 \\
50 \\
50 \\
60 \\
60 \\
60 \\
60 \\
60 \\
60\end{array}$ & $\begin{array}{l}\% \\
50 \\
75 \\
75 \\
50 \\
75 \\
81 \\
50 \\
75 \\
81\end{array}$ & $\begin{array}{c}\text { Days } \\
34 \\
3 \\
31 \\
12 \\
12 \\
12 \\
26 \\
26 \\
26\end{array}$ & $\begin{array}{l}\text { No spots. } \\
\text { Many spots, near white to pale pink. } \\
\text { Many spots resembling natural ones. } \\
\text { None. } \\
\text { Several yellowish spots. } \\
\text { Several yellowish spots. } \\
\text { Few spots. } \\
\text { More spots. } \\
\text { More spots, paper clips and staples se- } \\
\text { verely attacked. }\end{array}$ \\
\hline
\end{tabular}

Samples were placed in cartons so the emulsion lay against the sides and other short samples were laid emulsion down on the bottom of cartons in large desiccators. No acid was used. The results are given in table 8 . Corresponding control samples formed no blemishes under the same storage conditions. The tendency toward spot formation increased with humidity, as would be predicted on the basis of the paper degradation hypothesis and the results published by Marraccini and Kleinert. The effect of temperature was not as important as the effect of humidity.

TABLE 8. The effect of storage boxes on microfilm

\begin{tabular}{|c|c|c|c|}
\hline Temp. & $\begin{array}{l}\text { Relative } \\
\text { humidity }\end{array}$ & Time & Effect \\
\hline $\begin{array}{l}{ }^{\circ} \mathrm{C} \\
50 \\
60 \\
70 \\
50 \\
60 \\
60 \\
60 \\
60\end{array}$ & $\begin{array}{l}\% \\
50 \\
50 \\
50 \text { then } 75 \\
75 \\
75 \\
75 \\
81 \\
81\end{array}$ & $\begin{array}{l}\text { Days } \\
40 \\
55 \\
28 \text { then } 6 \\
38 \\
23 \\
41 \\
23 \\
41\end{array}$ & $\begin{array}{l}\text { No spots. } \\
\text { No spots. } \\
\text { None; then many spots. } \\
\text { Few white spots. } \\
\text { Few yellow spots. } \\
\text { Few yellow and white spots. } \\
\text { Several very similar to natural spots. } \\
\text { Large increase in yellow spot formation; } \\
\text { many spots similar to natural ones. }\end{array}$ \\
\hline
\end{tabular}

\subsection{Effect of Optical Density}

In the laboratory, the dependence of the tend ency to blemish formation on density could be readily observed. The results confirm the field observation. For example, on a density step tablet exposed to the very active stop-cock grease, there were no spots on the density steps 0.16 to 0.43 but spots on density steps 0.58 and above. The small density difference of 0.15 made the difference between spots and no spots. The degree of attack increased with density at densities above 0.58 .

\subsection{Effect of Gold Protective Treatment}

Henn and Wiest proposed a gold protective treatment for microfilms [1]. The chemistry of their proposal appears theoretically sound. Microfilms processed and given the gold protective treatment both during processing and after processing, in a commercial microfilm laboratory, have been studied. In all tests to date, the gold treated film has been consistently more resistant than untreated film to general attack by mild peroxides and has been virtually free of spot formation. The inertness of the gold treated image is demonstrated by its resistance to a short exposure to strong nitric acid. With severe and prolonged exposure to a peroxide atmosphere, the gold treated material is affected and, under these conditions, can even exhibit a resistance inferior to the untreated material, but it is questionable whether tests of this severity are pertinent to practice. Since this process has just recently been introduced commercially, there is little background of experience in practice.

\section{Recommendations}

Though our research on these blemishes has not been completed, those now engaged in microfilming and those planning records systems for the future have an immediate need for current information. Decisions with regard to expenditures of resources for the preservation of private and public records require value judgments based upon various considerations. However, since some technical judgments are involved, we offer the following suggestions and recommendations based upon our recent findings, past experience, and consultations with many people responsible for microfilming and preservation of records in Government and industry. The recommendations should be viewed in that perspective.

The blemish formation process, like all chemical processes, requires a combination of conditions. The elimination of one contributory factor may prevent the formation of blemishes under a given set of conditions, but we recommend, as a conservative policy, that all contributory factors be avoided, insofar as it is practical to do so. The following recommendations and suggestions are based upon this principle.

We recommend the use of film having a safety cellulose-ester base meeting applicable raw stock requirements, the viscosity retention requirement, and flexibility requirements of the American Standard Specifications for Photographic Films for Permanent Records [13] until that standard is revised.

The observation that the incidence and severity of blemishes tend to be greater on high-density areas suggests that for archival purposes it would be desirable to use no higher density than is required to serve the intended purpose, rather than strive for a high density for the sake of appearance.

Throughout the exposing and processing operations it is important to avoid scratching film, not only because scratches are undesirable in themselves but because blemishes form along scratches.

Since the processing conditions establish the conditions of the image and the gelatin, they play a role in establishing the probability of attack. The con- 
tributions of all the various processing conditions are not yet sufficiently well understood to warrant detailed recommendations with respect to all aspects of processing. Pope has reported that the presence of the iodide ion prevents most of the suliting of the image during fixing and aids in the elimination of residual chemicals during washing [15]. Henn, Wiest, and Mack [29] report that the presence of iodide in fixing baths was associated with a reduction or complete elimination of aging blemish formation in a number of private and Government processing plants. A private communication from Robert O. Bieling of Bell and Howell reported an increase in general fading on accelerated aging after such iodide treatment. This report has been confirmed at NBS. Since general fading has not, as of this time, been associated with the presence of iodide in the fixer in actual practice, the accelerated test may be too severe. On the other hand, the test may be predicting actual future performance. We have received no reports that general fading has ever been a problem to users of archival microfilm which was properly washed, while aging blemishes have actually destroyed small amounts of information in a few known cases. Since most microfilm images have rather high contrast, a considerable amount of general fading could be tolerated without loss of information. On the basis of these considerations, the addition of $0.2 \mathrm{~g}$ of potassium iodide per liter of fixing solution, to ixing solutions not otherwise containing an equivalent amount of iodide ion, appears desirable if the films are stored according to the recommendations given below.

Long experience as well as the results reported here of the effects of imbibed chemicals on microtilm support the conclusion that for archival purposes, film should be thoroughly washed to remove chemicals remaining after processing. Failure to do so invites general fading reactions and spot formation.

Efficient removal of water droplets before drying aids in preventing deposition of chemicals and promotes uniform drying, therefore, greater uniformity in image and gelatin characteristics. The nature of the drying process plays an important role in establishing the characteristics of the gelatin layer. The effects of time, temperature, humidity, and air velocity are not sufficiently well known to allow us to make detailed recommendations. Great care should be taken to avoid dust, fumes of any kind, and gases other than those in normal clean air.

We recommend that the American Standard Method for Determining the Thiosulfate Content of Processed Black-and-White Photographic Film and Plates be used until it is revised [28]. We suggest the method of Pope as an improvement for a revised standard [17].

The provisions of the American Standard Practice for Storage of Microfilm, [27] with the few variations noted in this paper, should be carefully observed.

The use of paper, string, adhesive tape, or rubber bands to bind the roll introduces chemical and physical variables which should be evaluated for each material. Such study may be justified if there is a real need for the use of such materials.

Chemicals or materials employed in splicing operations should be scrutinized carefully in light of the present findings. The use of such "foreign" materials can be avoided by the use of a thermally welded joint. This method is in satisfactory use in a Government agency which is one of the larger users of microfilm.

To avoid the peroxide generated in paper cartons and protect film from gases and vapors originating elsewhere, it is suggested that rolls of film be stored in sealed containers as defined in American Standard Practice for Storage of Microiflm [27]. Unpainted anodized aluminum appears to be a desirable material for containers. Hundreds of thousands of aluminum cans and reels have been used by one Government agency and they have been found practical and not too expensive. The reels were made of 0.051-in. thick anodized 2024 aluminum alloy and the cans were made of 0.032 -in. thick anodized 3003 aluminum alloy. The 2024 aluminum alloy provides the elasticity required for a reel to maintain its shape. Other materials should be scrutinized carefully, in the light of our indings. It should be borne in mind that spots were formed readily by amounts of material too small to be detected by a mass spectrograph which could detect concentrations corresponding to $10^{-7}$ to $10^{-9}$ moles per liter of the atmosphere sampled.

Low temperature and humidity appear to be desirable storage conditions. It is recommended that film to be in inactive storage be placed in the container in equilibrium with air at a relative humidity of 15 to 20 percent at 50 to $60{ }^{\circ} \mathrm{F}$, and that film for active îles be placed in the container in equilibrium with air at a relative humidity of 30 to 35 percent at 50 to $60{ }^{\circ} \mathrm{F}$. It is recommended that the storage temperature not be permitted to exceed $70^{\circ} \mathrm{F}$ and that it be maintained between 50 and $60^{\circ} \mathrm{F}$ where practical. Films may be stored at a lower temperature if they are warmed sufficiently before opening the container to avoid condensation of moisture on the film when the container is opened.

Archival films should not be exposed to sulfur dioxide, hydrogen sulfide, peroxides, volatile bases such as ammonia, volatile acids such as acetic acid, engine exhaust gases, or gaseous industrial wastes. The fumes from turpentine, linseed oil, or drying paints containing such materials should also be avoided. To prevent fingerprints, clean cloth gloves, available from dealers in photographic supplies, should be used whenever film is handled. The film should be handled by the edges, rather than the surfaces to avoid scratching the surfaces or depositing dust. Film handling equipment must be kept clean at all times and should be inspected periodically for cleanliness and any condition likely to scratch or otherwise damage film. Areas in which film is han- 
dled must be kept as clean and dust free as practical operations permit. Special air filtration and air washing may be required to avoid objectionable air-borne contaminants. Since the gaseous decomposition products evolved by nitrate-base films are very corrosive, such films should be removed from any building housing permanent records.

No aging blemishes have been observed on the information areas of positive prints having dark characters on a nearly clear background, although aging blemishes have been observed on the highdensity borders of one such film and others have been reported to us. For this reason the retention of such positive films is a recommended procedure when additional security is desired. A positive copy appears to be the best choice when only one film is to be retained in a permanent file and a positive copy will serve the intended purpose.

The probability of loss of information can be very greatly reduced by making more than one microfilm copy and preserving the copies in separate places.

The only positive assurance that records are being preserved is obtained by a regular program of inspection. This principle was recognized in the American Standard Practice for Storage of Microfilm adopted in 1957 [27]. Detailed sampling and inspection procedures are outlined in NBS Handbook $96[2]$. Experience has amply demonstrated that the routine satisfactory use of microfilms does not constitute adequate inspection. The attention of the user is on the information rather than the condition of the film and the optical nature of the blemishes makes them difficult to detect in the routine use of film. Undoubtedly there will now be a keener awareness of the condition of the film on the part of professional microfilm users, but systematic and well designed sampling and inspection are still necessary parts of record preservation. The sampling procedure should be regulated so that inspectors obtain a different sample each time. Careful inspection of each stratum every two years should reveal unsatisfactory conditions in time to allow appropriate action to be taken. After a number of years, if no problems have been encountered, this inspection period could be reasonably extended.

We recommend that existing collections of archival microfilm be stored under the same conditions recommended here for new archival microcopies. If the films have aging blemishes which appear to threaten legibility, the information on the films can be preserved by copying the films on permanent record materials and preserving the copies.

Nothing in these recommendations should be construed to mean that silver-gelatin type microfilm is the only possible material for archival record storage or that the roll form is necessarily preferred. There are, indeed, other possible materials but we have not conducted sufficient studies of their properties to make recommendations with respect to their use for the storage of records of permanent value.
This research was sponsored in part by the National Archives and Records Service, the Library of Congress, the Social Security Administration, the Navy Bureau of Weapons, and The Adjutant General's Office of the Department of the Army. In addition, the National Microfilm Association solicited and secured financial support from the Bell and Howell Company, E. I. DuPont de Nemours and Company, Dynacolor Corporation, International Business Machines, Minnesota Mining and Manufacturing Company, Recordak Corporation, University Microfilms, and Xerox Corporation.

The authors appreciate the cooperation of the sponsors and many other Government agencies that permitted access to records, supplied old films for research, permitted inspections and measurements to be made, and gave advice and helpful leads. A most cooperative spirit was found in the laboratories of the film manufacturers.

The photomicrographs were made by Myron Berkovitz. Miss Anna-Mary Bush assisted in the preliminary inspections and carried out the research on the Liesegang phenomenon.

\section{References}

[1] R. W. Henn and D. G. Wiest, Microscopic spots in processed microfilm: their nature and prevention, Phot. Sci. Eng. 7, 253 (1963).

[2] C. S. McCamy, Inspection of processed photographic record films for aging blemishes, National Bureau of Standards Handbook 96, (1964), U.S. Government Printing Office, Washingt on, D.C. 20402.

[3] B. W. Scribner, The protection of documents with cellulose acetate sheeting, NBS Misc. Publ. 168 (1940).

[4] Preservation of the Declaration of Independence and the Constitution of the United States, NBS Circular 505 (1951).

[5] W. K. Wilson and B. W. Forshee, Preservation of documents by lamination, NBS Mono. 5 (1959).

[6] J. R. Hill and C. G. Weber, Stability of motion-picture films as determined by accelerated aging, J. Res. NBS 1\%, 871 (1936).

[7] B. W. Scribner, Summary report of research at the National Bureau of Standards on the stability and preservation of records on photographic film, NBS Misc. Publ. 162 (1939).

[8] J. R. Hill and C. G. Weber, Evaluation of motionpicture film for permanent records, NBS Misc. Publ. 158 (1937).

[9] Public Law No. 788, 76th Congress, Chap. 727-3d Session, (H.R. 10026). Approved September 24, 1940.

[10] Public Law No. 115, 78th Congress, chap. 192-1st Session, (H.R. 2943). Approved July 7, 1943.

[11] Federal Records Act of 1950 . United States Code, Title 44, Sec. 399 (a).

[12] American Standard Specifications for Photographic Films for Permanent Records. Z38.3.2-1945. (American Standards Ássociation, New York).

[13] American Standard Specifications for Photographic Films for Permanent Records. PH1.28-1957. (American Standards Association, New York).

[14] Federal Standard 125a, Federal Standard Film, Photographic and Film, Photographic, Processed; (For Permanent Record Use) April 24, 1958.

[15] C. I. Pope, Formation of silver sulfide in the photographic image during fixation, J. Res. NBS 64C (Engr. and Instr.) No. 1, 65 (1960). 
[16] C. I. Pope, Stability of residual thiosulfate in processed microfilm, J. Res. NBS 67C (Engr. and Instr.) No. 1,15 (1963).

[17] C. I. Pope, Determination of residual thiosulfate in processed film, J. Res. NBS 67C (Engr. and Instr.) No. 3, 237 (1963).

[18] R. E. Liesegang, Naturw. Wichschr. 11, 353 (1896).

[19] R. E. Liesegang, Phot. Árchiv. 21, 221 (1896).

[20] K. H. Stern, The Liesegang phenomenon, Chem. Rev. 54 (1954).

[21] A. Wexler and S. Hasegawa, Humidity-temperature relationships of some saturated salt solutions in the temperature range 0 to $50{ }^{\circ} \mathrm{C}$, J. Res. NBS 53, 19 (1954) RP2512.

[22] D. S. Carr and L. B. Harris, Solutions for maintaining constant relative humidity, Ind. and Eng. Chem. p. 2015 (Sept. 1949).

[23] F. E. M. O'Brien, The control of humidity by saturated salt solutions, J. Sci. Inst. and Phys. in Ind. 25, 73 (1948).
[24] L. M. Marraccini and T. N. Kleinert, Spectrophotometric estimation of peroxide in cellulosic materials, pp. 78-80, Svensk Papperstidning 65, (Jan-June 1962).

[25] L. M. Marraceini and T. N. Kleinert, Aging and colour reversion of bleached pulps, ibid. p. 126-131.

[26] T. N. Kleinert and L. M. Marraccini, Aging and colour revision of bleached pulps, ibid. 66, (Jan-June 1963), p. 189-195.

[27] American Standard Practice for Storage of Microfilm. PH5.4-1957. (American Standards Association, New York).

[28] American Standard Method for Determining the Thiosulfate Content of Processed Black-and-White Photographic Film and Plates. PH4.8-1958. (American Standards Association, New York).

[29] R. W. Henn, D. G. Wiest, and Bernadette D. Mack, Microscopic spots in processed microfilm: the effect of iodide, Phot. Sci. Eng. 9, 167(1965).

(Paper 69A5-359) 